Polymer Journal Vol. 1, No. 4, pp 442-449 (1970)

\title{
Alternating Copolymerization of Butadiene and Acrylic Compounds
}

\author{
Junji Furukawa, Eiichi Kobayashi, ${ }^{*}$ Yutaka Iseda, ${ }^{* *}$ \\ and Yoshihiro ARAi* \\ Department of Synthetic Chemistry, Kyoto University, Kyoto, Japan.
}

(Received April 6, 1970)

\begin{abstract}
A kinetic investigation on the alternating copolymerization of butadiene (BD) and methyl methacrylate (MMA) was undertaken by using $\mathrm{EtAlCl}_{2}(\mathrm{Al})$ and $\mathrm{VOCl}_{3}$ (V) as catalysts. The rate orders with respect to both components were the same as those for the butadiene (BD)-acrylonitrile (AN) system as reported previously; the rate of polymerization, $R_{p, 0}$, is proportional to $[\mathrm{Al}]^{3 / 2}$ and $[\mathrm{V}]^{1 / 2}$, and the concentration of active species seems to be proportional to $[\mathrm{Al}]^{1 / 2}$ and $[\mathrm{V}]^{1 / 2}$.

These relations are interpreted in terms of the mechanism involving a rapid initiation followed by stepwise propagation through a BD-MMA-Al complexed monomer. The formation of a benzene-MMA-Al complex as well as a MMA-Al complex is supposed. The rate order with respect to $\mathrm{BD}$ and acrylic monomer (A) was found to be complicated, i.e., in the $\mathrm{BD}-\mathrm{AN}$ system $R_{p, 0}$ is proportional to [BD][AN] $]^{-2}$, whereas in the BD-MMA system $R_{p, 0}$ depends on neither [BD] nor [MMA]. This fact may be accounted for in terms of the equilibrium of the $\mathbf{B D}-\mathbf{A}-\mathrm{Al}$ complex and the $(\mathrm{A})_{n}-\mathrm{Al}$ complex. It is assumed that in a BD-AN-Al system the equilibrium constant for the $(\mathrm{AN})_{n}-\mathrm{Al}$ complex is very large, whereas in a MMA-BD-Al system the equilibrium constant for the (MMA) ${ }_{n}-\mathrm{Al}$ complex is smaller than that of the BD-MMA-Al complex.

KEY WORDS Alternating Copolymerization / Butadiene-Acrylonitrile / Butadiene-Methyl Methacrylate / Vanadyl Chloride-Ethylaluminum Dichloride / Rate / Molecular Weight / Mechanism / NMR of Copolymer/
\end{abstract}

A kinetic study on the alternating copolymerization of butadiene (BD) and acrylonitrile (AN) with an $\mathrm{EtAlCl}_{2}-\mathrm{VOCl}_{3}$ catalyst system was described in a previous report. ${ }^{1}$ The polymerization proceeds through a step-growth mechanism by the reaction of a growing radical with the $\mathrm{BD}-\mathrm{AN}-\mathrm{EtAlCl}_{2}$ complex. Vanadium compounds act not only as a regenerator of aluminum compounds but also as a cocatalyst forming a redox system with aluminum compounds.

However, the detailed mechanism of polymerization, especially the participation of monomer in the alternating copolymerization, is not yet discussed, since the polymer is sparingly soluble except in the reaction system containing a large

* Institute for Chemical Research, Kyoto University, Uji, Japan.

** Institute for Chemical Research, Kyoto University, Uji, Japan. On leave from Department of Research and Development, Bridgestone Tire Co., Ltd., Kodaira, Tokyo, Japan. amount of AN monomer.

This report deals with an alternating copolymerization of $\mathrm{BD}$ and methyl methacrylate (MMA) in relation to the BD-AN system, because the former polymer is quite soluble in the system in a wide range of monomer composition. A complex formation between MMA and $\mathrm{EtAlCl}_{2}$ and a ternary complex among MMA, benzene and $\mathrm{EtAlCl}_{2}$ were supposed.

\section{EXPERIMENTAL}

The procedure of the catalyst purification and the polymerization are almost the same as those in the preceding report ${ }^{1}$ unless otherwise described.

\section{Monomers}

The purification of $\mathrm{BD}$ and $\mathrm{AN}$ is the same as in the previous report ${ }^{1}$ and MMA is purified by conventional method. 


\section{Catalyst}

$\mathrm{E} \mathrm{AlCl}_{2}$ and $\mathrm{VOCl}_{3}$ are purified as previously.

\section{Polymerization}

The copolymerization of $\mathrm{BD}$ and $\mathrm{AN}$ is performed at $0^{\circ} \mathrm{C}$ in $n$-hexane with use of $\mathrm{EtAlCl}_{2}$ and $\mathrm{VOCl}_{3}$ as catalyst, whose concentrations are 80 or $58.7 \mathrm{mmol} / l$ and 4 or $2.39 \mathrm{mmol} / l$, respectively, AN and $\mathrm{BD}$ being in the range of $1.1-11.5 \mathrm{~mol} / l$ and $1.17-8.23 \mathrm{~mol} / l$, respective1y. The copolymerization of $\mathrm{BD}$ and MMA is carried out at $0^{\circ} \mathrm{C}$ in methylene chloride with EtAlCl ${ }_{2}, \mathrm{VOCl}_{3}, \mathrm{MMA}$, and $\mathrm{BD}$, whose concentrations are $44.3-221.7 \mathrm{mmol} / l, 0.44-8.87$ $\mathrm{mmol} / l, 0.15-7.50 \mathrm{~mol} / l$, and $0.33-6.00 \mathrm{~mol} / l$, respectively. The polymerization system is homogeneous in the whole reaction media investigated.

The number-average molecular weight of copolymer $\left(\bar{M}_{n}\right)$ of the resulting polymer was evaluated from the intrinsic viscosity $[\eta]$ according to the equation ${ }^{2}$

$$
[\eta]=3.91 \times 10^{-3} \times\left(\bar{M}_{n}\right)^{0.521}
$$

for $\mathrm{BD}-\mathrm{AN}$ copolymer. Here, the intrinsic viscosity of $\mathrm{BD}-\mathrm{AN}$ copolymer and $\mathrm{BD}-\mathrm{MMA}$ copolymer is measured at $30^{\circ} \pm 0.05^{\circ} \mathrm{C}$ with use of an Ubbelhode-type viscometer in N,Ndimethylformamide and toluene, respectively.

Table I. Effect of AN concentration on the alternating copolymerization by the $\mathrm{EtAlCl}_{2}-\mathrm{VOCl}_{3}$ catalyst at $0^{\circ} \mathrm{C}$

(a) Polymerization conditions

\begin{tabular}{ccccc}
\hline Expt no. & $\mathrm{AN}, \mathrm{mol} / l$ & $\mathrm{BD}, \mathrm{mol} / l$ & $\mathrm{EtAlCl}_{2}, \mathrm{mmol} / l$ & $\mathrm{VOCl}_{3}, \mathrm{mmol} / l$ \\
\hline 3N & 11.46 & 2.01 & 80.3 & 4.00 \\
3O & 9.16 & 2.01 & 80.3 & 4.00 \\
3P & 6.87 & 2.01 & 80.3 & 4.00 \\
3Q & 4.59 & 2.01 & 80.3 & 4.00 \\
\hline
\end{tabular}

(b) Results

\begin{tabular}{|c|c|c|c|c|}
\hline $\begin{array}{l}\text { Expt } \\
\text { no. }\end{array}$ & $\begin{array}{c}\text { Polymerization time, } \\
\mathrm{hr}: \min \end{array}$ & $\begin{array}{c}\text { Conversion, }{ }^{\mathrm{a}} \\
\%\end{array}$ & $\begin{array}{l}{[\eta]} \\
\mathrm{d} l / \mathrm{g}\end{array}$ & Reaction system \\
\hline $3 \mathrm{~N}-1$ & $1: 00$ & 3.0 & $0.40_{3}$ & \multirow{5}{*}{ Homogeneous solution } \\
\hline-2 & $2: 30$ & 5.6 & $0.45_{8}$ & \\
\hline-3 & $5: 03$ & 10.8 & $0.50_{0}$ & \\
\hline-4 & $10: 00$ & 17.9 & $0.53_{7}$ & \\
\hline-5 & $21: 30$ & 31.0 & $0.58_{3}$ & \\
\hline $30-1$ & $1: 05$ & 4.8 & $0.50_{8}$ & \multirow{5}{*}{ Heterogeneous } \\
\hline-2 & $2: 18$ & 11.0 & $0.64_{0}$ & \\
\hline-3 & $4: 00$ & 19.5 & $0.80_{6}$ & \\
\hline-4 & $8: 03$ & 30.1 & $0.85_{0}$ & \\
\hline-5 & $18: 45$ & 44.5 & $0.93_{2}$ & \\
\hline $3 \mathrm{P}-1$ & $0: 48$ & 11.0 & $0.96_{4}$ & \multirow{5}{*}{ Heterogeneous } \\
\hline-2 & $1: 10$ & 17.7 & $1.01_{6}$ & \\
\hline-3 & $2: 00$ & 24.1 & $1.04_{8}$ & \\
\hline-4 & $6: 00$ & 45.3 & $1.09_{3}$ & \\
\hline-5 & $17: 15$ & 57.6 & $1.22_{0}$ & \\
\hline $3 Q-1$ & $0: 21$ & 10.9 & $0.70_{0}$ & \multirow{5}{*}{ Heterogeneous } \\
\hline-2 & $0: 44$ & 22.5 & $0.83_{7}$ & \\
\hline-3 & $1: 30$ & 29.6 & $0.95_{6}$ & \\
\hline-4 & $4: 03$ & 44.7 & $1.11_{1}$ & \\
\hline-5 & $14: 45$ & 61.0 & $1.19_{0}$ & \\
\hline
\end{tabular}

a Based on $1: 1$ monomer. 


\section{J. Furukawa, E. Kobayashi, Y. Iseda, and Y. Arai}

Table II. Effect of AN/BD ration on the alternating copolymerization by the $\mathrm{EtAlCl}_{2}-\mathrm{VOCl}_{3}$ catalyst at $0^{\circ} \mathrm{C}$

(a) Polymerization conditions

\begin{tabular}{cccccc}
\hline $\begin{array}{c}\text { Expt } \\
\text { no. }\end{array}$ & $\begin{array}{c}\mathrm{BD}, \\
\mathrm{mol} / l\end{array}$ & $\begin{array}{c}\mathrm{AN}, \\
\mathrm{mol} / l\end{array}$ & $\begin{array}{c}\mathrm{EtAlCl}_{2}, \\
\mathrm{mmol} / l\end{array}$ & $\begin{array}{c}\mathrm{VOCl}_{3}, \\
\mathrm{mmol} / l\end{array}$ & $\begin{array}{c}\mathrm{AN} / \mathrm{BD}, \\
\text { molar ratio }\end{array}$ \\
\hline 4A & 1.17 & 10.57 & 58.7 & 2.93 & $90 / 10$ \\
4B & 3.52 & 8.23 & 58.7 & 2.93 & $70 / 30$ \\
4C & 5.87 & 5.87 & 58.7 & 2.93 & $50 / 50$ \\
4D & 8.23 & 3.52 & 58.7 & 2.93 & $30 / 70$ \\
\hline
\end{tabular}

(b) Results

\begin{tabular}{|c|c|c|c|c|}
\hline $\begin{array}{l}\text { Expt } \\
\text { no. }\end{array}$ & $\begin{array}{l}\text { Polymerization time, } \\
\text { hr : min }\end{array}$ & $\begin{array}{c}\text { Conversion, } \\
\%\end{array}$ & $\begin{array}{l}{[\eta]} \\
\mathrm{d} l / \mathrm{g}\end{array}$ & Reaction system \\
\hline $4 \mathrm{~A}-1$ & $1: 00$ & 3.1 & $0.39_{8}$ & \multirow{5}{*}{ Homogeneous solution } \\
\hline-2 & $2: 02$ & 5.8 & $0.44_{9}$ & \\
\hline-3 & $4: 10$ & 11.5 & $0.54_{8}$ & \\
\hline-4 & $8: 00$ & 19.7 & $0.56_{7}$ & \\
\hline-5 & $18: 00$ & 39.4 & $0.70_{0}$ & \\
\hline $4 \mathrm{~B}-1$ & $0: 45$ & 1.0 & $0.33_{8}$ & \multirow{5}{*}{ Heterogeneous } \\
\hline-2 & $1: 45$ & 2.4 & $0.59_{2}$ & \\
\hline-3 & $3: 32$ & 5.3 & $0.83_{6}$ & \\
\hline-4 & $7: 00$ & 9.3 & $0.91_{8}$ & \\
\hline-5 & $16: 00$ & 15.6 & $0.95_{8}$ & \\
\hline $4 C-1$ & $0: 25$ & 0.7 & $0.43_{7}$ & \multirow{4}{*}{ Heterogeneous } \\
\hline-2 & $1: 20$ & 2.6 & $0.91_{1}$ & \\
\hline-3 & $2: 07$ & 4.3 & $1.02_{2}$ & \\
\hline-4 & $4: 00$ & 6.9 & $1.14_{7}$ & \\
\hline $4 \mathrm{D}-1$ & $0: 10$ & 0.9 & $0.48_{8}$ & \multirow{5}{*}{ Heterogeneous } \\
\hline-2 & $0: 30$ & 3.5 & $0.65_{0}$ & \\
\hline-3 & $1: 00$ & 6.4 & $0.78_{4}$ & \\
\hline-4 & $2: 00$ & 9.6 & $0.92_{7}$ & \\
\hline-5 & $8: 00$ & 15.2 & $1.07_{0}$ & \\
\hline
\end{tabular}

\section{RESULTS}

Polymerization of Butadiene and Acrylonitrile

Because of the poor solubility of the resulting polymer, the polymerization was carried out in the reaction media containing a large amount of acrylonitrile in order to obtain the homogeneous reaction system. Nevertheless the polymerization system becomes heterogeneous and a polymer resembling an agar-agar form appears except No. 3N. When the reaction media contains a small amount of acrylonitrile, the reaction mixture also separates in two layers in which polymerization takes place mainly in the under layer. Consequently, the reaction may also be affected by the heterogeneity of the system at the high extent of the polymerization. Tables I and II summarize the result. From the above data an initial rate of polymerization $R_{p, 0}$ is calculated and plotted against the reciprocals of the square of AN concentration in the monomer solution. Figure 1 indicates that the rate is inversely proportional to a square of AN concentration, when the concentration of $\mathrm{BD}$ is kept constant. On the other hand, the first order rate with respect to the BD concentration was reported previously, ${ }^{1}$ and consequently.

$$
R_{p, 0} \propto[\mathrm{AN}]^{-2}[\mathrm{BD}]
$$

According to the preceding report,${ }^{1}$ the concentration of the active species $\left[\mathrm{C}^{*}\right]$ and the ratio 


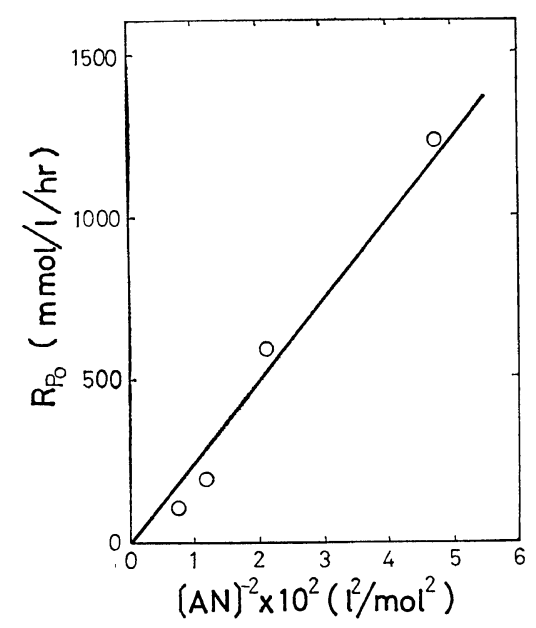

Figure 1. The plots of $R_{p, 0}$ against $[\mathrm{AN}]^{-2}$; taken from Table I.

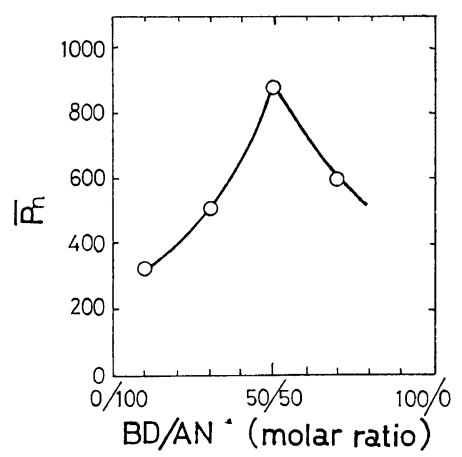

Figure 2. Effect of monomer composition on the degree of polymerization $\bar{P}_{n}$; taken from Table II.

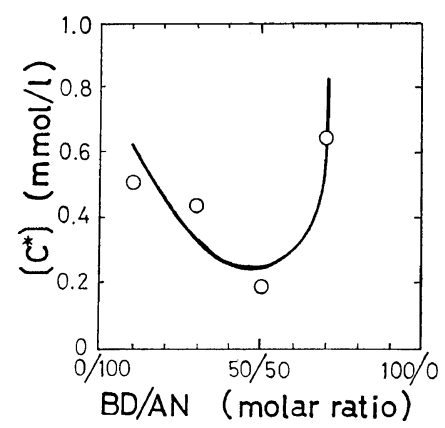

Figure 3. Effect of monomer composition on the concentration of active species [C*]; taken from Table II.

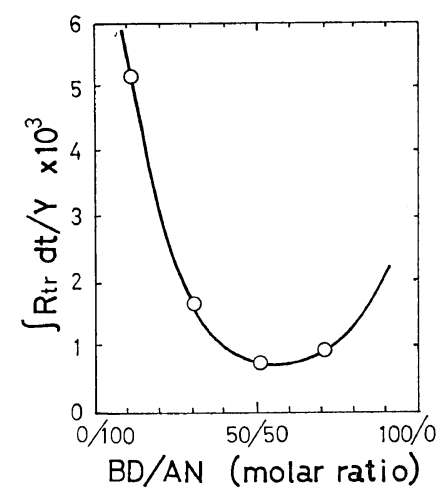

Figure 4. Effect of monomer composition on the transfer reaction; taken from Table II.

of the chain transfer to propagation are evaluated from the linear relations between $Y / \bar{P}_{n}$ and $Y$. The ratio thus estimated from the data listed in Table $\mathrm{I}$ is proportional to $[\mathrm{AN}] .{ }^{2.3}$ On the contrary, the monotonous relation between $\left[\mathrm{C}^{*}\right]$ and $[\mathrm{AN}]$ does not exist. The degree of polymerization $\left(\bar{P}_{n}\right)$ is increasing with increasing time of polymerization or yield $(Y)$ and that at a definite conversion was found to be correlated with the monomer composition.

Figures 2, 3 and 4 illustrate the variation of $\bar{P}_{n},\left[\mathrm{C}^{*}\right]$ and transfer/yield ratio as a function of the $[\mathrm{BD}] /[\mathrm{AN}]$ ratio. The degree of polymerization, $\bar{P}_{n}$, which is measured at $500 \mathrm{mmol} / l$ of polymer yield, attains its maximum value when the feed monomer composition is $1: 1$. This fact suggests that both monomers might participate in the initiation and the chain transfer reaction. As previously discussed, the number of the polymer molecule is given by the ratio of yield to the degree of polymerization and represented as follows

$$
\frac{Y}{\bar{P}_{n}}=\left[\mathrm{C}^{*}\right]+\int R_{t r} \mathrm{~d} t
$$

At a high extent of polymerization

$$
\bar{P}_{n} \doteqdot Y / \int R_{t r} \mathrm{~d} t
$$

and the maximum in Figure 2 and the minimum in Figure 4 may be ascribed to the same origin. Since the propagation reaction is proportional to the concentration of $1: 1$ monomer complex, the degree of polymerization may 
J. Furukawa, E. Kobayashi, Y. Iseda, and Y. Arai

Table III. Copolymerization of BD with MMA in $\mathrm{CH}_{2} \mathrm{Cl}_{2}$ at $0^{\circ} \mathrm{C}$

(a) Experimental conditions

\begin{tabular}{rrrrr}
\hline $\begin{array}{c}\text { Expt } \\
\text { no. }\end{array}$ & $\begin{array}{r}\mathrm{MMA}, \\
\mathrm{mol} / \mathrm{l}\end{array}$ & $\begin{array}{c}\mathrm{BD}, \\
\mathrm{mol} / \mathrm{l}\end{array}$ & $\begin{array}{r}\mathrm{EtAlCl}_{2}, \\
\mathrm{mmol} / l\end{array}$ & $\begin{array}{c}\mathrm{VOCl}_{3}, \\
\mathrm{mmol} / l\end{array}$ \\
\hline $\mathrm{Al}-1$ & 2.22 & 2.22 & 44.3 & 8.87 \\
-2 & 2.22 & 2.22 & 88.6 & 8.87 \\
-3 & 2.22 & 2.22 & 221.7 & 8.87 \\
\hline $\mathrm{V}-1$ & 2.22 & 2.22 & 88.7 & 0.443 \\
-2 & 2.22 & 2.22 & 88.7 & 0.887 \\
-3 & 2.22 & 2.22 & 88.7 & 1.18 \\
\hline $\mathrm{M}-1$ & 0.15 & 1.50 & 60 & 3.0 \\
-2 & 0.30 & 1.50 & 60 & 3.0 \\
-3 & 0.75 & 1.50 & 60 & 3.0 \\
-4 & 1.50 & 1.50 & 60 & 3.0 \\
-5 & 3.75 & 1.50 & 60 & 3.0 \\
-6 & 7.50 & 1.50 & 60 & 3.0 \\
\hline $\mathrm{B}-1$ & 1.50 & 0.334 & 60 & 3.0 \\
-2 & 1.50 & 0.667 & 60 & 3.0 \\
-3 & 1.50 & 1.50 & 60 & 3.0 \\
-4 & 1.50 & 3.0 & 60 & 3.0 \\
-5 & 1.50 & 6.0 & 60 & 3.0 \\
\hline
\end{tabular}

(b) Results

\begin{tabular}{|c|c|c|c|c|c|c|c|c|}
\hline $\begin{array}{l}\text { Expt } \\
\text { no. }\end{array}$ & $\underset{\mathrm{mol} / l}{\mathrm{MMA}}$ & $\begin{array}{l}\mathrm{BD} \\
\mathrm{mol} / l\end{array}$ & $\begin{array}{l}\mathrm{EtAlCl}_{2} \\
\mathrm{mmol} / l\end{array}$ & $\begin{array}{l}\mathrm{VOCl}_{3} \\
\mathrm{mmol} / l\end{array}$ & $\begin{array}{l}\text { Expt } \\
\text { no. }\end{array}$ & $\begin{array}{c}\text { Polymerization } \\
\text { time, hr }\end{array}$ & $\begin{array}{l}\text { Yield, } \\
\operatorname{mmol} / l\end{array}$ & $\begin{array}{l}{[\eta]} \\
\mathrm{d} l / \mathrm{g}\end{array}$ \\
\hline Al-1 & 2.22 & 2.22 & 44.3 & 8.87 & \multirow[t]{4}{*}{ M-4 } & 7 & 75 & 0.78 \\
\hline-2 & 2.22 & 2.22 & 88.6 & 8.87 & & 12 & 139 & 1.12 \\
\hline-3 & 2.22 & 2.22 & 221.7 & 8.87 & & 20 & 187 & 1.13 \\
\hline \multirow{3}{*}{$\begin{array}{r}\mathrm{V}-1 \\
-2 \\
-3\end{array}$} & \multirow{3}{*}{$\begin{array}{l}2.22 \\
2.22 \\
2.22\end{array}$} & \multirow{3}{*}{$\begin{array}{l}2.22 \\
2.22 \\
2.22\end{array}$} & \multirow{3}{*}{$\begin{array}{l}88.7 \\
88.7 \\
88.7\end{array}$} & \multirow{3}{*}{$\begin{array}{l}0.443 \\
0.887 \\
1.18\end{array}$} & & 40 & 344 & \\
\hline & & & & & \multirow[t]{5}{*}{ M-5 } & 2 & 88 & - \\
\hline & & & & & & 11 & 113 & 0.65 \\
\hline \multirow{5}{*}{$\begin{array}{r}\text { M-1 } \\
-2 \\
-3 \\
-4 \\
-5 \\
-6\end{array}$} & \multirow{5}{*}{$\begin{array}{l}0.15 \\
0.30 \\
0.75 \\
1.50 \\
3.75 \\
7.50\end{array}$} & \multirow{5}{*}{$\begin{array}{l}1.50 \\
1.50 \\
1.50 \\
1.50 \\
1.50 \\
1.50\end{array}$} & 60 & \multirow{5}{*}{$\begin{array}{l}3.0 \\
3.0 \\
3.0 \\
3.0 \\
3.0 \\
3.0\end{array}$} & & 30 & 114 & 1.07 \\
\hline & & & 60 & & & 40 & 411 & 1.65 \\
\hline & & & 60 & & & 50 & 421 & 1.78 \\
\hline & & & $\begin{array}{l}60 \\
60\end{array}$ & & M-6 & 1.5 & 21 & 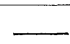 \\
\hline & & & 60 & & & 3 & 74 & 0.27 \\
\hline \multirow{5}{*}{$\begin{array}{r}\text { B-1 } \\
-2 \\
-3 \\
-4 \\
-5\end{array}$} & \multirow{5}{*}{$\begin{array}{l}1.50 \\
1.50 \\
1.50 \\
1.50 \\
1.50\end{array}$} & \multirow{5}{*}{$\begin{array}{l}0.334 \\
0.667 \\
1.50 \\
3.0 \\
6.0\end{array}$} & 60 & \multirow{5}{*}{$\begin{array}{l}3.0 \\
3.0 \\
3.0 \\
3.0 \\
3.0\end{array}$} & & 13 & 112 & 0.52 \\
\hline & & & 60 & & & 40 & 211 & 1.27 \\
\hline & & & 60 & & & & & \\
\hline & & & 60 & & $\mathrm{~V}-1$ & 3 & 46 & $\longrightarrow$ \\
\hline & & & 60 & & & 6 & 102 & 0.41 \\
\hline \multicolumn{5}{|c|}{ (b) Results } & & 24 & 243 & 1.50 \\
\hline \multirow{2}{*}{$\begin{array}{l}\text { Expt } \\
\text { no. }\end{array}$} & \multirow{2}{*}{\multicolumn{2}{|c|}{$\begin{array}{l}\text { Polymerization } \\
\text { time, hr }\end{array}$}} & & & \multirow{4}{*}{$\mathrm{V}-2$} & 48 & 500 & 1.10 \\
\hline & & & $\mathrm{mmol} / \mathrm{l}$ & $\begin{array}{l}{[\eta],} \\
\mathrm{d} l / \mathrm{g}\end{array}$ & & $\begin{array}{l}3 \\
6\end{array}$ & $\begin{array}{l}55 \\
87\end{array}$ & $\begin{array}{l}0.32 \\
0.38\end{array}$ \\
\hline \multirow[t]{4}{*}{ Al-1 } & \multirow{4}{*}{\multicolumn{2}{|c|}{$\begin{array}{r}6 \\
12 \\
24 \\
47 \\
70\end{array}$}} & - & - & & $\begin{array}{l}12 \\
24\end{array}$ & $\begin{array}{l}185 \\
265\end{array}$ & $\begin{array}{l}0.88 \\
1.21\end{array}$ \\
\hline & & & $\overline{128}$ & 0.44 & & $\begin{array}{l}24 \\
48\end{array}$ & $\begin{array}{l}265 \\
509\end{array}$ & $\begin{array}{l}1.21 \\
1.60\end{array}$ \\
\hline & & & 280 & 0.66 & V-3 & 3 & 98 & 0.31 \\
\hline & & & 412 & 0.73 & $\sqrt{-3}$ & 6 & 94 & 0.39 \\
\hline \multirow{4}{*}{ Al-2 } & & & - & - & & $\begin{array}{l}12 \\
24\end{array}$ & $\begin{array}{l}200 \\
358\end{array}$ & $\begin{array}{l}0.97 \\
1.14\end{array}$ \\
\hline & & & 113 & 0.41 & & $\begin{array}{l}24 \\
48\end{array}$ & 606 & $\begin{array}{l}1.14 \\
1.50\end{array}$ \\
\hline & & & 459 & 0.84 & B-1 & 5 & 44 & 0.44 \\
\hline & & & 796 & 0.84 & & 10 & 129 & 0.91 \\
\hline $\mathrm{A} 1-3$ & & & 166 & - & & $\begin{array}{l}20 \\
43\end{array}$ & $\begin{array}{l}191 \\
395\end{array}$ & $\begin{array}{l}1.20 \\
1.17\end{array}$ \\
\hline Nit & & & 396 & 0.80 & & 72 & 616 & 0.98 \\
\hline & & & $\begin{array}{r}840 \\
1491\end{array}$ & 0.97 & B-2 & 4 & 37 & 0.57 \\
\hline & & & $\begin{array}{l}1491 \\
2857\end{array}$ & 1.17 & & 10 & $\begin{array}{r}69 \\
183\end{array}$ & 0.92 \\
\hline$M-1$ & & & 71 & 0.30 & & 30 & 217 & 1.26 \\
\hline & & & 121 & 0.34 & & 72 & 286 & 1.16 \\
\hline & & & 191 & 0.30 & B-3 & 3 & 35 & 0.36 \\
\hline & & & 232 & 0.31 & & 8 & 91 & 0.82 \\
\hline & & & 241 & 0.29 & & 15 & 159 & 0.98 \\
\hline M-2 & & & $\begin{array}{r}96 \\
151\end{array}$ & 0.46 & & $\begin{array}{l}27 \\
50\end{array}$ & $\begin{array}{l}285 \\
562\end{array}$ & $\begin{array}{l}1.07 \\
1.27\end{array}$ \\
\hline & & & 211 & 0.60 & B-4 & 2 & $\longrightarrow$ & - \\
\hline & & & 273 & 0.54 & & 4 & 25 & $\square$ \\
\hline & & & 356 & 0.47 & & 10 & $\begin{array}{r}79 \\
55\end{array}$ & 0.73 \\
\hline$M-3$ & & & 19 & $\overline{0}$ & & 40 & 330 & 0.99 \\
\hline & & & $\begin{array}{l}106 \\
172\end{array}$ & $\begin{array}{l}0.71 \\
0.78\end{array}$ & B-5 & 1 & $\longrightarrow$ & $\longrightarrow$ \\
\hline & & & $\begin{array}{l}1 / 2 \\
271\end{array}$ & $\begin{array}{l}0.18 \\
0.85\end{array}$ & & 3 & $\longrightarrow$ & 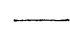 \\
\hline & & & 390 & 0.82 & & $\begin{array}{r}8 \\
18\end{array}$ & $\begin{array}{r}57 \\
163\end{array}$ & 0.55 \\
\hline$M-4$ & & & 23 & - & & 40 & 208 & $\longrightarrow$ \\
\hline
\end{tabular}


attain its maximum at this point in so far as the effect of monomer composition of the other elementary processes in the polymerization is not large.

Polymerization of Butadiene and Methyl Methacrylate

The polymerization was carried out similarly as in the preceding chapter. Table III summarizes the result. The logarithmic plots of the initial rate of polymerization $R_{p, 0} v s$. concentration of the aluminum compounds $[\mathrm{Al}]$, or the vanadium compound [V] afford linear relations as shown in Figure 5. In other words, the rate

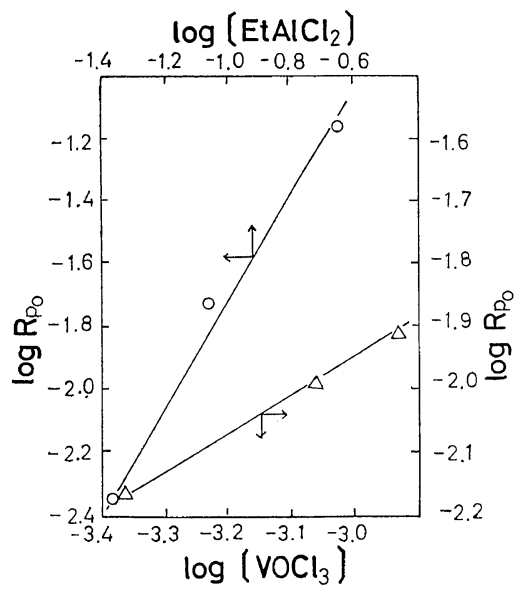

Figure 5. The relation between $\log R_{p, 0}$ and $\log$ $\left[\mathrm{EtAlCl}_{2}\right]$ and $\log \left[\mathrm{VOCl}_{3}\right]$; taken from Table III.

is proportional to both $[\mathrm{V}]^{1 / 2}$ and $[\mathrm{Al}]^{3 / 2}$, i.e.,

$$
R_{p, 0} \propto[\mathrm{V}]^{1 / 2}[\mathrm{Al}]^{3 / 2}
$$

Eq 2 is quite similar to that for the polymerization of BD and AN reported previously, ${ }^{1}$ and rewritten in the following forms

$$
\begin{aligned}
R_{p, 0} & \propto\left[\mathrm{C}^{*}\right] \times[\text { complexed monomer }] \\
& \propto[\mathrm{Al}]^{3 / 2}[\mathrm{~V}]^{1 / 2}
\end{aligned}
$$

and

$$
\left[\mathrm{C}^{*}\right] \propto[\mathrm{Al}]^{1 / 2}[\mathrm{~V}]^{1 / 2}
$$

Consequently, it follows that

$$
\text { [Complexed monomer }] \propto[\mathrm{Al}]
$$

This means that the complexed monomer involves one mole of aluminum component.

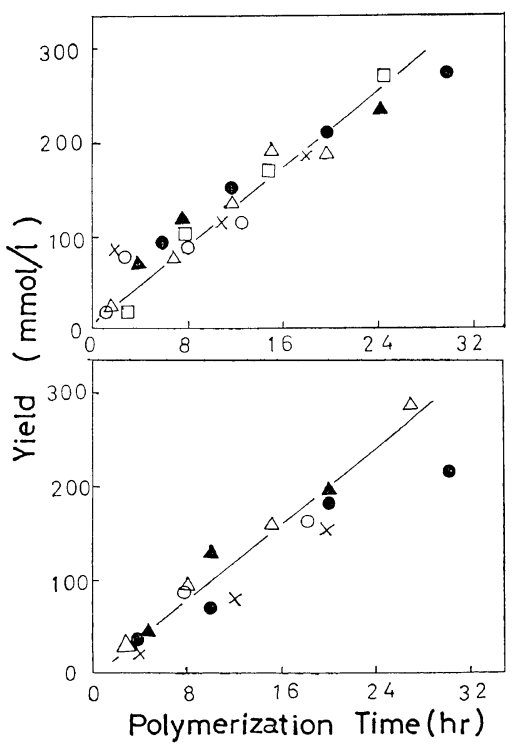

Figure 6. Effect of MMA (above) and BD (below) concentration on the polymerization time-polymer yield curves; taken from Table III.

The dependence of the rate on the concentrations of each monomer is demonstrated in Figure 6. It was found that the rate of polymerization is constant irrespective of the polymerization time and the initial concentration of monomers.

$$
R_{p, 0} \propto[\mathrm{MMA}]^{0}[\mathrm{BD}]^{0}
$$

It is to be noticed that eq 6 is quite different from eq 1 for the butadiene-acrylonitrile copolymerization. The intrinsic viscosity $[\eta]$ of the resulting polymer has a maximum value at $1: 1$

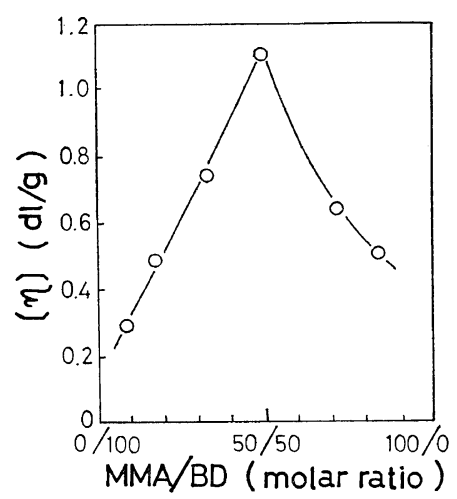

Figure 7. Effect of monomer composition on the $[\eta]$ of polymer obtained; taken from Table III. 
MMA : BD ratio and this is quite similar to the case of the acrylonitrile-butadiene system, as shown in Figure $7 .[\eta]$ was evaluated with the polymer obtained at the polymerization time for $12 \mathrm{hr}$.

The alternating structure of the resulting co-
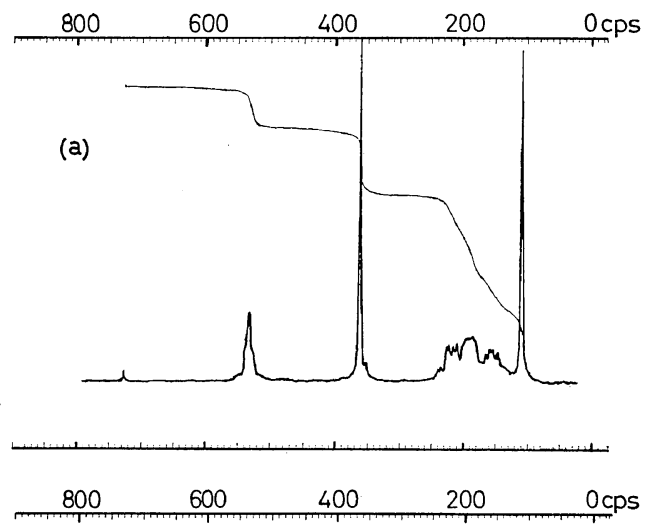

(b)

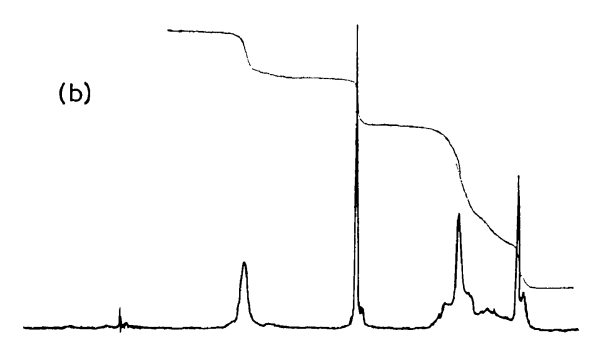

Figure 8. The NMR spectra of BD-MMA copolymers at $60^{\circ} \mathrm{C}$ in $\mathrm{CDCl}_{3}$ : (a) alternate copolymer prepared by $\mathrm{EtAlCl}_{2}-\mathrm{VOCl}_{3}$ system, (b) random copolymer prepared by BPO.

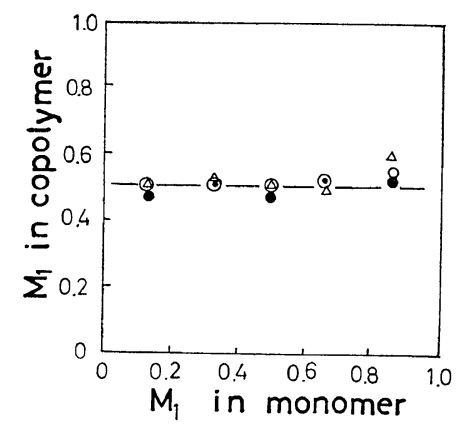

Figure 9. Copolymer composition curves obtained by $\mathrm{EtAlCl}_{2}-\mathrm{VOCl}_{3}: \quad\left[\mathrm{EtAlCl}_{2}\right] /\left[\mathrm{VOCl}_{3}\right] ; \quad 0,50 / 1$; $\Delta, 30 / 1 ; \bullet, 10 / 1$. polymer was estimated from the 100-Mc NMR spectra. The spectra contain no absorption at $7.98 \tau$ due to the butadiene-butadiene dyad, and $\alpha-\mathrm{CH}_{3}$ proton's signal of MMA is singlet as illustrated in Figure 8; the MMA unit may exist in the MMA-BD dyad but not in the MMA-MMA dyad.

The formation of alternate copolymer irrespective of monomer feed ratio is shown in Figure 9 and this fact indicates that the complexed monomer polymerizes preferentially.

\section{DISCUSSION}

The kinetic data indicate that the dependency of the catalyst concentration on the copolymerization rate of butadiene and methyl methacrylate is the same as that of butadiene and acrylonitrile as reported previously. ${ }^{1}$ Consequently, the present copolymerization proceeds through the mechanism analogous to that for the previous one. It is likely that the active species is proportional both to the square root of aluminum and vanadium compounds, and this suggests that rapid initiation takes place through a redox mechanism between both catalyst components. The chain growth is stepwise and $\boldsymbol{R}_{p}$ is proportional to the concentration of active species and of active monomers. It seems reasonable to assume from the kinetic data that the active monomer is a complex of aluminum compound and both monomers. In fact, the cryoscopic study suggests the presence of a complex of $(\mathrm{AN})_{2} \cdot \mathrm{EtAlCl}_{2}$ and the NMR analysis indicates the formation of a ternary complex consisting of benzene, MMA and $\mathrm{EtAlCl}_{2}{ }^{3}$

On the other hand, there is a great difference in the dependency of monomer concentrations on the copolymerization rate for each copolymerization, as expressed in eq 1 and 6 . If one assumes the equilibrium formation of two different catalyst-monomer complexes, namely, the $1: 1: 1$-complex among butadiene (BD), acrylic compound (A) and aluminum compound (Al) and the $n: 1$-complex between acrylic and aluminum compound, the concentration of the former complex is expressed as follows

$$
[\mathrm{BD}-\mathrm{A}-\mathrm{Al}]=\frac{K_{1}[\mathrm{BD}][\mathrm{A}][\mathrm{Al}]}{1+K_{1}[\mathrm{BD}][\mathrm{A}]+K_{2}[\mathrm{~A}]^{n}}
$$


where $K_{1}$ and $K_{2}$ are the equilibrium constants of the formation of the $1: 1: 1$ - and $n: 1$-complexes, respectively. Eq 1 or 6 can be derived from eq 7 when $K_{2} \gg K_{1}, 1$ or $K_{1} \gg K_{2}$, 1 , respectively, viz.,

$$
[\mathrm{BD}-\mathrm{A}-\mathrm{Al}] \fallingdotseq\left(K_{1} / K_{2}\right)[\mathrm{Al}][\mathrm{BD}] /[\mathrm{A}]^{n-1}
$$

or

$$
[\mathrm{BD}-\mathrm{A}-\mathrm{Al}] \fallingdotseq[\mathrm{Al}]
$$

It is likely that $K_{2} \gg K_{1}$ for butadiene and acrylonitrile systems because acrylonitrile is very basic and much more acrylonitrile is complexed to the aluminum compounds as compared with the case of butadiene and methyl methacrylate. In the latter case, it is also reasonable to assume that $K_{1} \gg K_{2}$. The kinetic studies indicate that the $K_{2}$ of the BD-AN system is larger than that of the BD-MMA system, and the ternary complex such as $\mathrm{Al}-\mathrm{MMA}-\mathrm{BD}$ seems to be easily formed, although quantitative studies on the complex formation between monomers and
Lewis acid are necessary to confirm the above proposal.

As other evidence, it is noteworthy that when AN, MMA and BD (1:1:4 in molar ratio) exist together within a polymerization system, the copolymer composition obtained is the 12 : $39: 49$ in molar ratio. ${ }^{4}$ It is likely that the formation of the Al-MMA-BD complex occurs more readily than that of the $\mathrm{Al}-\mathrm{AN}-\mathrm{BD}$ complex.

Acknowledgement. We are grateful to Miss K. Giga for assistance with experiments.

\section{REFERENCES}

1. J. Furukawa, E. Kobayashi, and Y. Iseda, Polymer J., 1, 155 (1970).

2. T. Yoshimoto, et al., unpublished data.

3. J. Furukawa, Y. Iseda, and E. Kobayashi, $J$. Polym. Sci., Part B, in press.

4. J. Furukawa, Y. Iseda, K. Haga, and N. Kataoka, J. Polym. Sci. Part A-1, 8, 1147 (1970). 